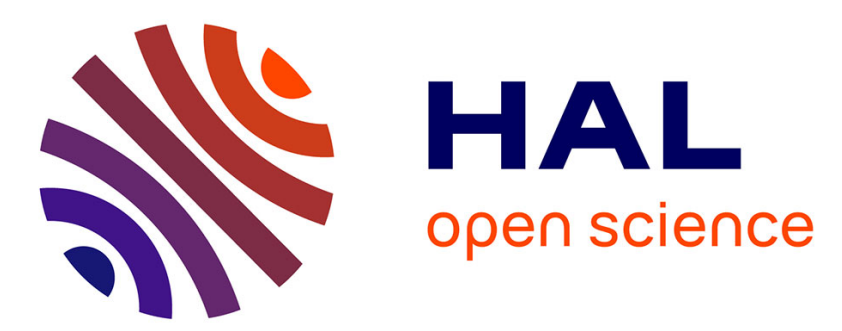

\title{
Asymmetric synthesis of hetero-1,2,3,4,5-pentasubstituted ferrocenes
}

\author{
William Erb, Thierry Roisnel
}

\section{To cite this version:}

William Erb, Thierry Roisnel. Asymmetric synthesis of hetero-1,2,3,4,5-pentasubstituted ferrocenes. Chemical Communications, 2019, 55 (62), pp.9132-9135. 10.1039/c9cc04604f . hal-02278407

\section{HAL Id: hal-02278407 https://hal-univ-rennes1.archives-ouvertes.fr/hal-02278407}

Submitted on 18 Nov 2019

HAL is a multi-disciplinary open access archive for the deposit and dissemination of scientific research documents, whether they are published or not. The documents may come from teaching and research institutions in France or abroad, or from public or private research centers.
L'archive ouverte pluridisciplinaire HAL, est destinée au dépôt et à la diffusion de documents scientifiques de niveau recherche, publiés ou non, émanant des établissements d'enseignement et de recherche français ou étrangers, des laboratoires publics ou privés. 


\title{
Asymmetric synthesis of hetero-1,2,3,4,5-pentasubstituted ferrocenes
}

\author{
William Erb* and Thierry Roisnel
}

The first synthesis of enantioenriched ferrocenes bearing five different substituents on the same cyclopentadienyl ring is described through unprecedented asymmetric halogen 'dance'. Not only this work extends the chemistry of fluoroferrocene derivatives and constitutes the very first entry into the world of enantioenriched hetero-pentasubstituted ferrocenes, it also lays the ground for researches in other metallocene families.

Since the discovery of ferrocene,,$^{1,2}$ its derivatives have found applications in all areas of chemistry. ${ }^{3-5}$ However, while monosubstituted, 1,1'- and 1,2-disubstituted ferrocenes account for a large number of reported applications, there is a need for highly substituted derivatives as the controlled introduction of various substituents allows their electronic ${ }^{6-9}$ and steric ${ }^{10,11}$ properties to be finely modulated. Albeit usual in metallocene chemistry, ${ }^{12-14}$ pentamethylcyclopentadienyl (Cp*) and pentaphenylcyclopentadienyl ligands do not offer, with their five identical substituents, a high degree of properties' tuning. Thus, there are currently very few 1,2,3,4,5pentasubstituted ferrocenes bearing functional groups other than hydrocarbyls. Achiral 1,2,3,4,5-pentahalogenoferrocenes $(\mathrm{Cl}, \mathrm{Br}, \mathrm{F})$ are accessible in a few steps, ${ }^{15-20}$ while iterative metalation-functional group manipulation allows the tedious syntheses of pentasubstituted ferrocenes bearing up to three different substituents (Scheme 1). ${ }^{21-23}$

Here, we report how the wise choice of substituents can enable hetero-1,2,3,4,5-pentasubstituted ferrocenes to be delivered, either as racemates or enantioenriched products, marking a milestone in metallocene science (Scheme 1).

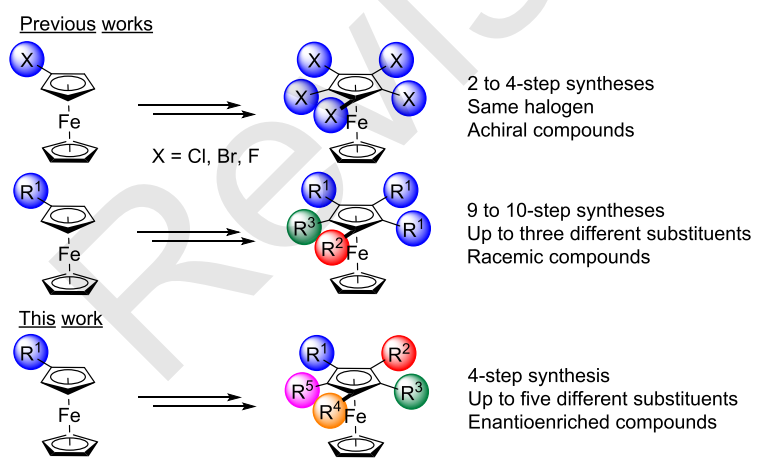

Scheme 1. Original approach toward enantioenriched hetero1,2,3,4,5-pentasubstituted ferrocene derivatives.

Dr. William Erb, Dr. Thierry Roisnel

Univ Rennes, CNRS, ISCR (Institut des Sciences Chimiques de Rennes)

UMR 6226, F-35000 Rennes, France.

E-mail:william.erb@univ-rennes1.fr
Our plan relies on the use of halogens able to act either as directing or as migrating groups in deprotolithiation and halogen 'dance' reaction, ${ }^{24,25}$ as we recently reported on simpler ferrocene substrates. ${ }^{26} \mathrm{~A}$ polar substituent, namely the dimethylaminomethyl group, was selected to overcome separation issues and make the multistep approach efficient.

To validate our strategy, we thus started from racemic 1,2,3trisubstituted ferrocene ( \pm )-1. ${ }^{26}$ Indeed, fluorine being a strong acidifying directing group, we had to temporary protect its adjacent position by a trimethylsilyl group from deprotometalation. Therefore, when treated with LiTMP (TMP $=2,2,6,6$-tetramethylpiperidino) at low temperature in THF ( $\mathrm{THF}=$ tetrahydrofuran), the isomerization occurred smoothly to deliver ( $\mathbf{(})-\mathbf{2}$ in $84 \%$ yield after interception with Eschenmoser's salt (Scheme 2). As compound ( $\mathbf{\pm}$ )-2 proved reluctant to further deprotometalation next to the bulky trimethylsilyl group, we had to replace it by a directing group and selected chlorine for its acidifying properties. The silyl group was successfully removed by reaction with tetrabutylammonium fluoride (compound ( \pm )-3, 89\% yield), and consecutive LiTMP-mediated deprotometalation and interception with hexachloroethane provided the tetrasubstituted compound $(\mathbf{(})-\mathbf{4}$ (86\% yield). A final reaction with LiTMP followed by interception with dimethylformamide afforded the original pentasubstituted ferrocene $( \pm)-5$, sensitive to light and air, in $48 \%$ yield. We also isolated the sensitive dialdehyde ( \pm )- 6 in $8 \%$ yield, probably resulting from further iodine/lithium exchange.

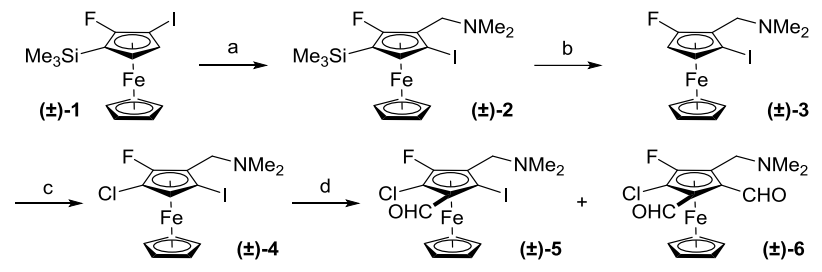

Scheme 2. Synthesis of ( \pm )-5. Reaction conditions: a) LiTMP, THF, -50 ${ }^{\circ} \mathrm{C}$, $90 \mathrm{~min}$ then Eschenmoser's salt, $-78{ }^{\circ} \mathrm{C}$ to $\mathrm{rt}, 84 \%$; b) Tetrabutylammonium fluoride, THF, rt, $5 \mathrm{~min}, 89 \%$; c) LiTMP, THF, $78{ }^{\circ} \mathrm{C}, 1 \mathrm{~h}$ then hexachloroethane, $-78{ }^{\circ} \mathrm{C}$ to rt, $86 \%$; d) LiTMP, THF, $78{ }^{\circ} \mathrm{C}, 1 \mathrm{~h}$ then dimethylformamide, $-78{ }^{\circ} \mathrm{C}$ to $0{ }^{\circ} \mathrm{C}$, ( \pm )- $548 \%$, ( \pm )- 6 $8 \%$.

The first hetero-pentasubstituted ferrocene derivative obtained as racemate, access to its enantioenriched counterpart was next studied. However, the current synthetic route toward ( \pm )$\mathbf{1}$ is based on the deprotometalation of fluoroferrocene, ${ }^{26}$ a reaction that would be hardly feasible enantioselectively. ${ }^{27}$ Furthermore, if we successfully prepared 1-fluoro-2- 
dimethylaminoferrocene from fluoroferrocene, its resolution turned out to be not productive in our hands and forced us to turn to another approach. The enantioselective metalation of (dimethylaminomethyl)ferrocene described by Strohmann with reported $90 \%$ ee was appealing, but to complete the asymmetric synthesis of pentasubstituted ferrocene in the most efficient way, we required enantiopure starting material. ${ }^{28}$ Therefore, we moved to a diastereoselective synthesis and selected Ugi's amine, ${ }^{29}$ one of the most known ferrocene derivatives bearing a chiral directing group. ${ }^{5}$

A first approach, involving the halogen 'dance' reaction on a trisubstituted ferrocene as exemplified above, was evalutated in the racemic series. By following a literature protocol, ${ }^{30}$ Ugi's amine ( $\mathbf{\pm})-7$ was reacted with $s B u L i$ before addition of hexachloroethane to deliver the new chlorinated ferrocene ( \pm )8 in $96 \%$ yield (Scheme 3 ). This was reacted with an excess of LiTMP in the presence of $\mathrm{ZnCl}_{2} \cdot$ TMEDA (TMEDA $=N, N, N^{\prime}, N^{\prime}$ tetramethylethylenediamine) as in situ trap ${ }^{31}$ before iodolysis to give ( \pm ) -9 , isolated in a moderate $56 \%$ yield. However, a better result was noticed by using 3 equivalents of LiTMP without in situ trap ( $80 \%$ yield). By applying our standard halogen 'dance' reaction conditions (1.1 equiv of LiTMP, $-50{ }^{\circ} \mathrm{C}$, $2 \mathrm{~h}$ contact time) before the addition of trimethylsilyl chloride, the tetrasubstituted ferrocene ( $\mathbf{\pm})-\mathbf{1 0}$ was isolated in $\mathbf{5 9 \%}$ yield without traces of other isomers, highlighting the ability of chlorine to control the isomerization. However, when submitted to the action of LiTMP, the desired deprotometalation did not occur and LiTMP promoted iodine/lithium exchange was noticed, as revealed after trapping with phenyl isocyanate (compound ( \pm )-11, 9.5\% yield, $64.5 \%$ yield brsm). ${ }^{32}$

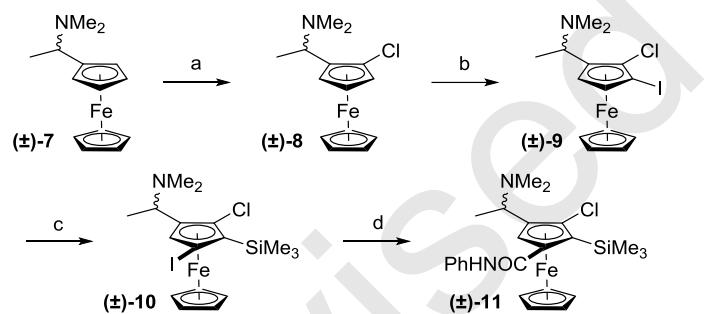

Scheme 3. Synthesis of ( \pm )-11. Reaction conditions: a) $s \mathrm{BuLi} \mathrm{Et}_{2} \mathrm{O}, 0$ ${ }^{\circ} \mathrm{C}, 1 \mathrm{~h}$ then hexachloroethane, $-78{ }^{\circ} \mathrm{C}$ to $0{ }^{\circ} \mathrm{C}, 96 \%$; b) LiTMP, THF, $35^{\circ} \mathrm{C}, 2 \mathrm{~h}$ then $\mathrm{I}_{2},-35^{\circ} \mathrm{C}$ to $0^{\circ} \mathrm{C}, 80 \%$; C) LiTMP, THF, $-50{ }^{\circ} \mathrm{C}, 2 \mathrm{~h}$ then trimethylsilyl chloride, $-78{ }^{\circ} \mathrm{C}$ to $\mathrm{rt}, 59 \%$; d) LiTMP, THF, $-35^{\circ} \mathrm{C}, 2 \mathrm{~h}$ then phenyl isocyanate, $-35^{\circ} \mathrm{C}$ to $\mathrm{rt}, 9.5 \%, 64.5 \% \mathrm{brsm}$. brsm $=$ based on recovery of starting material.

The reason why deprotometalation did not happen remains unclear. However, it might be postulated that weak ferrocene hydrogen acidity and improper steric factors can account for this result. Even if solid state structures do not necessarily reflect the conformations in solution, $\mathrm{X}$-ray diffraction analysis of $(\mathbf{\pm}) \mathbf{- 1 0}$ revealed that the bulky silyl group pushes the iodine atom closer to the last ferrocene hydrogen and that the $\alpha$ methyl group is close to the plane of the upper cyclopentadienyl (Cp) ring (Figure 1, left), thus shielding the last ferrocene hydrogen from the base.
To access a pentasubstituted ferrocene, both a less sterically demanding substrate and more acidic hydrogens are required. This could be achieved by introducing a fluorine atom instead of the silyl group. Thus, ( \pm )-8 was reacted with an excess of LiTMP before addition of $\mathrm{N}$-fluorobenzenesulfonimide (NFSI) as the fluorine source toward ( $\mathbf{\pm}$ )-12 (Scheme 4). Although isolated in a moderate $26 \%$ yield, ${ }^{33}$ this constitutes the first example of disubstituted ferrocene fluorination. The trisubstituted ferrocene ( \pm )-12 was then treated with LiTMP at $-78^{\circ} \mathrm{C}$ for $1 \mathrm{~h}$ before addition of iodine, resulting in the formation of the tetrasubstituted derivative ( $\mathbf{\pm})-\mathbf{1 3}$, isolated in $\mathbf{9 1 \%}$ yield. When subjected to our classical halogen 'dance' reaction conditions (1.1 equiv of LiTMP, $-50^{\circ} \mathrm{C}, 2 \mathrm{~h}$ contact time) before addition of trimethylsilyl chloride, formation of the desired pentasubstituted ferrocene $(\mathbf{t})-\mathbf{1 4}$ was noticed (10\% isolated yield; $32 \%$ brsm yield). Pleasingly, by increasing both the amount of base and reaction time, we managed to isolate up to $69 \%$ of compound ( \pm )-14. The tetrasubstituted compound ( \pm )15 , resulting from an iodine/lithium exchange as encountered above, ${ }^{32}$ was isolated in $15 \%$ yield.

The choice of substituents and their introduction order being validated in the racemic series, the asymmetric route was next investigated by starting from $\left(\boldsymbol{R}, \boldsymbol{S}_{\boldsymbol{p}}\right)-\mathbf{8}$, easily accessible from commercially available $(\boldsymbol{R})-\mathbf{7}$ by following a literature protocol. ${ }^{30}$ Fluorine and iodine atoms were introduced one after the other, compounds $\left(\boldsymbol{R}, \boldsymbol{R}_{p}\right)-\mathbf{1 2}$ and $\left(\boldsymbol{R}, \boldsymbol{S}_{p}\right)-\mathbf{1 3}$ being isolated as single diastereoisomers. The halogen 'dance' reaction was finally attempted to deliver the ferrocenes $\left(\boldsymbol{R}, \boldsymbol{S}_{\boldsymbol{p}}\right)-\mathbf{1 4}$ and $\left(\boldsymbol{R}, \boldsymbol{R}_{p}\right)-\mathbf{1 5}$ in $53 \%$ and $11 \%$ yield, respectively. As only one diastereoisomer was detected by ${ }^{1} \mathrm{H}$ NMR, this constitutes the very first example of asymmetric halogen 'dance' reaction.

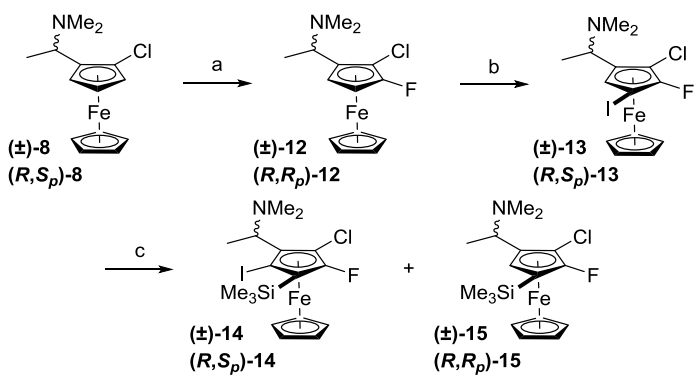

Scheme 4. Synthesis of $( \pm)$ - and $\left(R, S_{p}\right)-14$. Reaction conditions: a) LiTMP, THF, $-35^{\circ} \mathrm{C}, 2 \mathrm{~h}$ then NFSI, THF, $-35^{\circ} \mathrm{C}$, ( \pm$)-1226 \%,\left(\boldsymbol{R}, \boldsymbol{R}_{p}\right)-12$ $26 \%$; b) LiTMP, THF, $-78{ }^{\circ} \mathrm{C}, 1 \mathrm{~h}$ then $\mathrm{I}_{2},-78^{\circ} \mathrm{C}$ to rt, $( \pm)-1391 \%,\left(R, S_{p}\right)-$ $1385 \%$; d) LiTMP, THF, $-50{ }^{\circ} \mathrm{C}, 4 \mathrm{~h}$ then trimethylsilyl chloride, $-50^{\circ} \mathrm{C}$ to rt, ( \pm )-14 69\%, ( \pm )-15 15\%, $\left(R, S_{p}\right)-14$ 53\%, $\left(R, R_{p}\right)-1511 \%$.

To avoid any remaining doubt concerning the optical purity of the derivatives prepared, they were subjected to chiral HPLC analysis. Unfortunately, despite all our efforts, no efficient resolution could be reached. As the dimethylamino substituent seemed to impair proper separation, it was substituted by an acetate group by heating $( \pm)$ - or $\left(\boldsymbol{R}, \boldsymbol{S}_{p}\right)-\mathbf{1 4}$ in acetic anhydride at $110^{\circ} \mathrm{C}$. Full conversion was noticed after $1 \mathrm{~h}$ reaction time but ${ }^{1} \mathrm{H}$ NMR analysis revealed that some epimerization occurred, and mixtures of diastereoisomers in 1:3 and 1:4.5 ratios were identified for $(\mathbf{t})-\mathbf{1 6}$ and $\left(\boldsymbol{R}, \boldsymbol{S}_{\boldsymbol{p}}\right)$-16 respectively (Scheme 5 ). 
Chiral HPLC separation revealed a $99.5 \%$ ee and $63 \%$ de for $\left(R, S_{p}\right)-16$, thus validating the first synthesis of enantioenriched hetero-1,2,3,4,5-pentasubstituted ferrocene derivative.

As planar chirality was not expected to be lost at this stage, we reasoned that epimerization of the tertiary carbon occurred. However, on such highly functionalized derivatives, the origin of this phenomena is not obvious. Although the formation of a transient fulvene is now well established on simpler substrates, ${ }^{34,35}$ such intermediate might be disfavored in our case, for steric or electronic reasons. It is also known that, on specific substrates, the kinetic carbocation formed can isomerize toward the most stable one. ${ }^{36}$ Exploring such possibilities requires detailed studies that will be reported in due time. ${ }^{37}$

To complete this study, we finally reacted $( \pm)$ - and $\left(\boldsymbol{R}, \boldsymbol{S}_{p}\right)$-14 with iodomethane and obtained the corresponding ( \pm )- and $\left(R, S_{p}\right)-\mathbf{1 7}$ derivatives in quantitative yields. Substitution of the ammonium by various nucleophiles would afford $N, O$ or $P$ substituted original ferrocenes. ${ }^{29,38,39}$

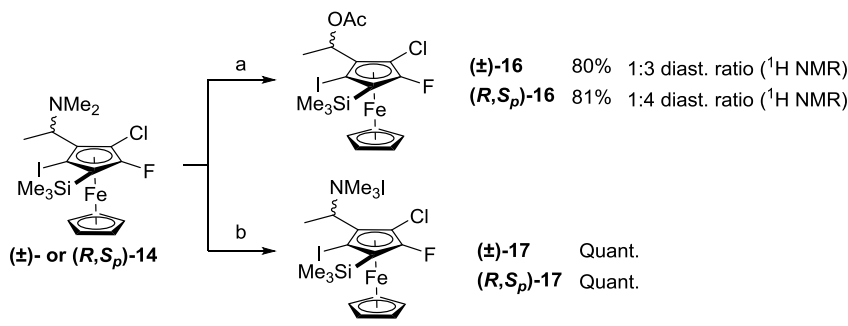

Scheme 5. Post-functionalization of $( \pm)$ - and $\left(\boldsymbol{R}, \boldsymbol{S}_{p}\right)-14$. Reaction conditions: a) $\mathrm{Ac}_{2} \mathrm{O}, 1 \mathrm{~h}, 110^{\circ} \mathrm{C}$; b) $\mathrm{Mel}, \mathrm{CH}_{3} \mathrm{CN}, 1 \mathrm{~h}$, rt.

Apart from the aldehydes $\mathbf{5}$ and $\mathbf{6}$, all substituted ferrocenes prepared in the course of this study were found to be stable in the solid state and in solution. However, solutions of compounds 12, 16 and 17 were of limited stability upon exposure to air and light as darkening was noticed, as well as broadening of peaks in ${ }^{1} \mathrm{H}$ NMR spectroscopy.

$X$-ray diffraction analysis of $\left(\boldsymbol{R}, \boldsymbol{S}_{p}\right)$-13 revealed interesting features when compared to $(\mathbf{t})$-10 (Figure 1 , right). Indeed, due to the smaller fluorine atom, the remaining ferrocene hydrogen appears less shielded by both the iodine and the $\alpha$-methyl group. Added to the acidifying effect of fluorine, this might explain why $\left(\boldsymbol{R}, \boldsymbol{S}_{p}\right)-\mathbf{1 3}$ is more prone to deprotometalation than $( \pm)-10$. Otherwise, the three carbon-halogen bonds are in the range of classical values while the two $\mathrm{Cp}$ rings are in an eclipsed configuration $\left(\mathrm{C}^{7}-\mathrm{Cg}^{1 \cdots} \mathrm{Cg}^{2}-\mathrm{C}^{3}\right.$ pseudo torsion angle $0.2^{\circ}, \mathrm{Cg}$ denoting the centroids of the respective $\mathrm{Cp}$ ring) and close to coplanarity (Cp-Cp planes angle $\left.4.6^{\circ}\right)$.
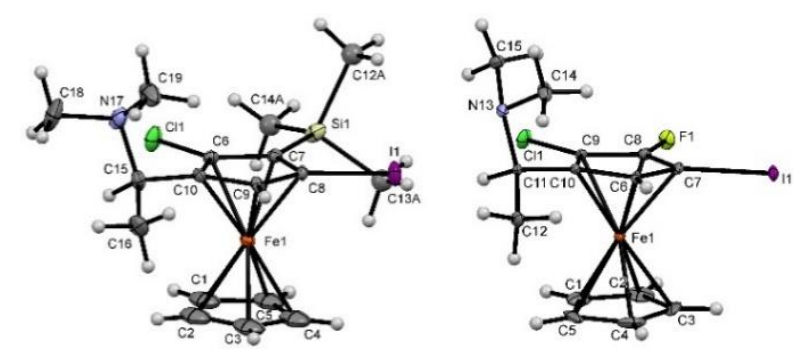

Figure 1. Left and right: molecular structure of compound ( \pm )-10 and $\left(R, S_{p}\right)-13$ (thermal ellipsoids shown at the $30 \%$ probability level). Selected geometrical structure parameters for $( \pm)-10:\left.\mathrm{H}^{6 \ldots}\right|^{1}$ distance 3.24 (5) $\AA, C^{7}-C^{8}-I^{1}$ angle $127.2^{\circ}, C^{10}-C^{8}-I^{1}$ angle $121.2^{\circ}, C^{10}-C^{9}-C^{15}-C^{16}$ torsion angle $29.1^{\circ}$. Selected geometrical structure parameters for $\left(R, S_{p}\right)$-13: $\left.\mathrm{H}^{6 \ldots} \ldots\right|^{1}$ distance 3.35 (4) $\AA$, $\mathrm{C}^{8}-\mathrm{C}^{7}-\left.\right|^{1}$ angle $126.8^{\circ}, \mathrm{C}^{6}-\mathrm{C}^{7}-\left.\right|^{1}$ angle $126.3^{\circ}, C^{6}-C^{10}-C^{11}-C^{12}$ torsion angle $40.1^{\circ}, C 7 \cdots \mid 12.10$ (4) $\AA$,

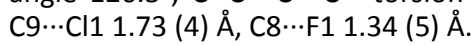

There are very few solid-state structures of pentasubstituted ferrocene derivatives in the literature. ${ }^{17,19,40}$ Pleasingly, we were able to grow a crystal of $\left(\boldsymbol{R}, \boldsymbol{S}_{p}\right)$-14 suitable for X-ray diffraction analysis (Figure 2 ). In the solid state, the three carbon-halogen bonds appear in the usual range of length and almost coplanar with the $\mathrm{Cp}$ ring while the $\alpha$-methyl group points toward the iron atom. Contrary to other pentasubstituted ferrocenes, ${ }^{17,19,40}$ the two $\mathrm{Cp}$ rings appear in a staggered conformation $\left(\mathrm{C}^{9}-\mathrm{Cg}^{1} \cdots \mathrm{Cg}^{2}-\mathrm{C}^{2}\right.$ pseudo torsion angle $25.3^{\circ}$ ) but almost coplanar ( $\mathrm{Cp}-\mathrm{Cp}$ angle $\left.2.2^{\circ}\right)$. Finally, the iron atom was found slightly closer to the substituted $\mathrm{Cp}$ ring than to the unsubstituted one.

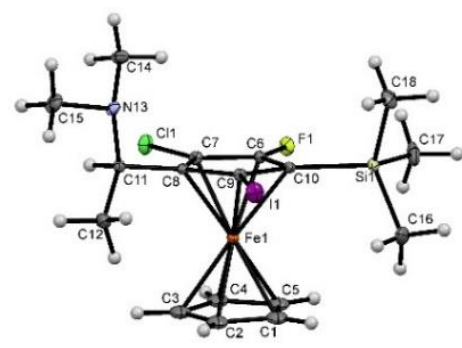

Figure 2. Molecular structure of compound $\left(\boldsymbol{R}, \boldsymbol{S}_{p}\right)-\mathbf{1 4}$ (thermal ellipsoids shown at the $30 \%$ probability level). Selected geometrical structure parameters: $C^{9}-C^{10}-C^{11}-C^{12}$ torsion angle $57.1^{\circ}, C 9 \cdots \mid 12.10$

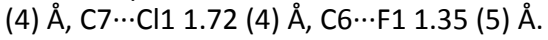

In conclusion, the rational choice of both the substituents and their introduction order onto ferrocene allowed the synthesis of the first examples of hetero-1,2,3,4,5-pentasubstituted ferrocene derivatives. By using Ugi's amine as chiral starting material, we managed to achieve the first synthesis of an enantioenriched pentasubstituted ferrocene with $99.5 \%$ ee. Key steps involve the original fluorination of a disubstituted ferrocene derivative and the first asymmetric halogen 'dance' reaction. We also obtained evidence that, on specific substrates, lithium amide-promoted halogen/metal exchange can become a competitive reaction when deprotometalation is not favored. Substitution of the dimethylamino group by an acetate was performed, highlighting an unexpected 
epimerization of the tertiary center that will require detailed studies while the full physicochemical study of the highly functionalized ferrocene derivatives is currently ongoing. Rovis' recent account demonstrated the interest to have highly substituted cyclopentadienyl ligands to control both reactivities and selectivities in metal-catalyzed transformations. ${ }^{41}$ Therefore, as ferrocene chemistry can be applied to other metallocenes, this work lays the ground for a general approach toward enantioenriched highly substituted metallocene compounds to uncover unexplored chemical space where new molecules endowed with original bioactivities or catalytic properties undoubtedly lie.

This work was supported by the Université de Rennes 1 and CNRS. We gratefully acknowledge the Fonds Européen de Développement Régional (FEDER; D8 VENTURE Bruker AXS diffractometer), Rennes Métropoles (ThermoFischer Ultimate 3000 apparatus) and Thermofisher (generous gift of 2,2,6,6 tetramethylpiperidine and (R)-(-)-N,N-dimethyl-1-ferrocenylethylamine (L)-tartrate). W.E. would like to thank Prof. F. Mongin for support, critically reviewing this document and making valuable suggestions.

\section{Conflicts of interest}

There are no conflicts to declare.

\section{Notes and references}

1. T. J. Kealy and P. L. Pauson, Nature, 1951, 168, 1039.

2. S. A. Miller, J. A. Tebboth and J. F. Tremaine, J. Chem. Soc., 1952, 632.

3. Ferrocenes: Homogeneous Catalysis, Organic Synthesis, Materials Science, A. Togni and T. Hayashi, Eds. VCH: Weinheim, 1995.

4. Ferrocenes: Ligands, Materials and Biomolecules, P. Štěpnička, Ed. Wiley: Chichester, 2008.

5. Chiral Ferrocenes in Asymmetric Catalysis, L.-X. Dai and X.-L. Hou, Eds. Wiley-VCH: Weinheim, 2010.

6. D. A. Khobragade, S. G. Mahamulkar, L. Pospíšil, I. Císařová, L. Rulíšek and U. Jahn, Chem. Eur. J., 2012, 18, 12267.

7. Š. Toma and R. Šebesta, Synthesis, 2015, 47, 1683.

8. S. D. Waniek, J. Klett, C. Förster and K. Heinze, Beilstein J. Org. Chem., 2018, 14, 1004.

9. R. Pietschnig, Chem. Soc. Rev., 2016, 45, 5216.

10. F. O. Arp and G. C. Fu, J. Am. Chem. Soc., 2006, 128, 14264.

11. X. Wang, R. Fröhlich, C. G. Daniliuc, B. Rieger, A. Jonovic, G. Kehr and G. Erker, Organometallics, 2012, 31, 6741.

12. P. Jutzi, Comments Inorg. Chem., 1987, 6, 123.

13. W. J. Evans and B. L. Davis, Chem. Rev., 2002, 102, 2119.

14. C. Bruneau, J.-L. Renaud and B. Demerseman, Chem. Eur. J., 2006, 12, 5178.

15. F. L. Hedberg and H. Rosenberg, J. Am. Chem. Soc., 1973, 95, 870.

16. I. R. Butler, Inorg. Chem. Commun., 2008, 11, 484.

17. K. Sünkel and S. Bernhartzeder, J. Organomet. Chem., 2011, 696, 1536.

18. S. Bernhartzeder and K. Sünkel, J. Organomet. Chem., 2012, 716, 146.
19. K. Sünkel, S. Weigand, A. Hoffmann, S. Blomeyer, C. G. Reuter, Y. V. Vishnevskiy and N. W. Mitzel, J. Am. Chem. Soc., 2015, 137, 126.

20. H. Butenschön, Synthesis, 2018, 50, 3787.

21. W. Steffen, M. Laskoski, J. G. M. Morton and U. H. F. Bunz, J. Organomet. Chem., 2004, 689, 4345.

22. I. R. Butler, B. Woldt, M.-Z. Oh and D. J. Williams, Inorg. Chem. Commun., 2006, 9, 1255

23. G. Werner and H. Butenschön, Organometallics, 2013, 32, 5798.

24. M. Schnurch, M. Spina, A. F. Khan, M. D. Mihovilovic and P. Stanetty, Chem. Soc. Rev., 2007, 36, 1046.

25. W. Erb and F. Mongin, Tetrahedron, 2016, 72, 4973.

26. M. Tazi, M. Hedidi, W. Erb, Y. S. Halauko, O. A. Ivashkevich, V. E. Matulis, T. Roisnel, V. Dorcet, G. Bentabed-Ababsa and F. Mongin, Organometallics, 2018, 37, 2207.

27. R. A. Ewin, A. M. MacLeod, D. A. Price, N. S. Simpkins and A. P. Watt, J. Chem. Soc., Perkin Trans. 1, 1997, 401.

28. P. Steffen, C. Unkelbach, M. Christmann, W. Hiller and C. Strohmann, Angew. Chem. Int. Ed., 2013, 52, 9836.

29. D. Marquarding, H. Klusacek, G. Gokel, P. Hoffmann and I. Ugi, J. Am. Chem. Soc., 1970, 92, 5389.

30. M. Watanabe, S. Araki, Y. Butsugan and M. Uemura, J. Org. Chem., 1991, 56, 2218.

31. N. M. Brikci-Nigassa, G. Bentabed-Ababsa, W. Erb and F. Mongin, Synthesis, 2018, 50, 3615.

32. F. Mongin, E. Marzi and M. Schlosser, Eur. J. Org. Chem., 2001, 2001, 2771.

33. K. Sünkel and S. Weigand, Inorg. Chim. Acta, 2011, 370, 224.

34. R. Gleiter and R. Seeger, Helv. Chim. Acta, 1971, 54, 1217.

35. C. Bleiholder, F. Rominger and R. Gleiter, Organometallics, 2009, 28, 1014.

36. A. Brunner, S. Taudien, O. Riant and H. B. Kagan, Chirality, 1997, 9, 478 .

37. An elimination-addition mechanism could also account for the epimerization. However, such a possibility was discarded as no change in the de was noticed upon heating ( \pm )-16 in acetic anhydride for $1 \mathrm{~h}$.

38. N. Chavain, E. Davioud-Charvet, X. Trivelli, L. Mbeki, M. Rottmann, R. Brun and C. Biot, Biorg. Med. Chem., 2009, 17, 8048.

39. M. A. Schmidt, E. M. Simmons, C. S. Wei, H. Park and M. D. Eastgate, J. Org. Chem., 2018, 83, 3928.

40. K. Sünkel, U. Birk, A. Blum and W. Kempinger, J. Organomet. Chem., 1994, 465, 167.

41. T. Piou and T. Rovis, Acc. Chem. Res., 2018, 51, 170. 